\title{
Desarrollo: perspectiva ética y cristiana
}

\section{Ildefonso Camacho, S.J.'}

Resumen: Las páginas que siguen parten de un convencimiento: que el desarrollo no es solo una cuestión técnica y socioeconómica, sino que encierra una dimensión ética. Pero este convencimiento no estaba tan asentado cuando se empezó a hablar de desarrollo y se pusieron en marchas las primeras estrategias para hacerlo realidad, a mediados del siglo $X X$. Fue obra de quienes comenzaron a tomar cierta distancia crítica frente a políticas que pretendían "el desarrollo" para preguntarse "¿qué desarrollo?". Porque la reflexión ética suele activarse cuando empezamos a sentirnos incómodos con la realidad que nos circunda.

También el término "ética" requiere alguna puntualización. ¿̨ué ética? Desde la perspectiva del que esto escribe la respuesta a esa pregunta distinguiría, al menos, una ética natural (basada en tradiciones filosóficas diferentes) y una ética cristiana (entre otras posibles éticas derivadas de tradiciones religiosas). Aunque habría que matizar todavía más esta distinción, de momento vale para explicar el enfoque que daremos a este trabajo, que viene sugerido por la propia trayectoria personal de su autor. Esta trayectoria puede esquematizarse así: desde el pensamiento social cristiano (en adelante, PSC) se ha buscado la conexión y el diálogo con el pensamiento ético filosófico en sus diferentes orientaciones. Esta relación implica dos cosas: que el PSC no puede entenderse si no es desde la realidad en que se elabora (no es un saber atemporal, aunque a veces se presente así) y de las lecturas que se hacen de ella; que ese pensamiento cristiano tiene también aspectos específicos que aportar derivados de su carácter propio y de la tradición religiosa en que se sustenta. El diálogo a que aludimos, por tanto, mantiene la diferencia entre las dos partes y en esa diferencia radica su fecundidad.

La aportación del PSC al desarrollo puede sintetizarse en este momento en la siguiente fórmula: desarrollo humano integral, solidario y sostenible. Pero esta formulación no es fruto de una intuición momentánea, sino resultado de un proceso de décadas. En ese

\footnotetext{
${ }^{1}$ Facultad de Teología. Universidad Loyola Andalucía.

${ }^{2}$ Sobre la importancia de esta aportación, puede verse L. KELEHER, 2019.
} 
proceso ha habido una interacción doble: ante todo, con la realidad de la pobreza y el subdesarrollo en un mundo cada vez más desigual; además, un diálogo con las distintas propuestas teóricas que fueron surgiendo para explicar cómo avanzar hacia el desarrollo de los pueblos, qué obstáculos se deberían evitar, cuáles eran las causas que impedían a los países más pobres salir de su situación...

Para visualizar este proceso tomaremos como referencia tres momentos del PSC vinculados a documentos oficiales de la lglesia, pero en cada uno de esos momentos haremos referencia al contexto histórico y a las principales tendencias en el pensamiento sobre el desarrollo y sobre la ética del desarrollo. Porque el pensamiento de la lglesia, que no se puede entender ignorando estas relaciones, ha contribuido con sus aportaciones a la elaboración de una ética del desarrollo hecha desde perspectivas no religiosas.

\section{Development: an ethical and Christian perspective}

Abstract: The following pages are founded
on one conviction: that development is not
simply a technical or socio-economical issue
but that it involves an ethical dimension.
This idea, however, was not well established
when development first became the subject
of debate, and first strategies were designed
to turn it into a reality during the mid-20th
century. It was the work of those who took a
certain critical distance in the face of policies
supposed to promote development, in order
to ask the question as to what development
actually meant. The reason for this is that
ethical reflection tends to emerge when we
begin to feel uneasy with the reality that
surrounds us.

\section{Développement: perspective éthique et chrétienne}

Résumé: Les pages qui suivent reposent sur la conviction que le développement $n^{\prime}$ est pas seulement une question technique et socioéconomique, mais qu'il a aussi une dimension éthique. Mais cette conviction n'était pas aussi bien ancrée lorsquel'on a commencé à parler de développement et que les premières stratégies pour le concrétiser ont été mises en place au milieu du XXe siècle. C'est l'œuvre de ceux qui ont commencé à prendre une distance critique par rapport aux politiques qui se réclamaient du «développement» pour se demander «quel développement?». Parce que la réflexion éthique est généralementactivée lorsque nous commençons à nous sentir mal à l'aise avec la réalité qui nous entoure. 


\section{Los años 1960-1970: primeros pasos en la elaboración de una ética del desarrollo - La aportación del Concilio Vaticano II y del papa Pablo VI}

Tomamos como referencia para esta etapa tres textos oficiales de la Iglesia: la Constitución Pastoral sobre la Iglesia en el mundo de hoy, Gaudium et spes, de 1965 (en adelante, GS), la Carta encíclica sobre la necesidad de promover el desarrollo de los pueblos, Populorum progressio, de 1967 (en adelante, PP); el documento del Sínodo Mundial de Obispos, celebrado en Roma en 1971, La justicia en el mundo. Nuevas responsabilidades de la iglesia en el campo de la justicia (en adelante, JM). Pero antes es oportuno asomarnos al contexto en que este pensamiento se desarrolla.

\section{I.I. El desarrollo de los pueblos tras el final de la segunda guerra mundial}

Tomar como punto de partida para este análisis la segunda guerra mundial se justifica por las nuevas condiciones del mundo una vez concluida esta. Al menos tres fenómenos hay que destacar directamente relacionados con la cuestión del desarrollo, en unos momentos en que los niveles de bienestar alcanzados en los países industrializados se convierte en aspiración para esos países recién constituidos: ante todo, la generalización de los procesos de descolonización, que dota a estos nuevos países de una autonomía desde la que parece más fácil buscar un desarrollo efectivo; en segundo lugar, la fase expansiva de la economía mundial (impulsada inicialmente por el Plan Marshall), como oportunidad única de la que podrían aprovecharse todos; por último, la amenaza del comunismo como alternativa para esos países emergentes, que es contemplada con inquietud por los países occidentales.

Tomar como modelo los países ya desarrollados implica identificar ese desarrollo anhelado con un incremento del PIB (que automáticamente se traduciría en un aumento de la renta media). La pregunta central era sencillamente: ¿̇cómo avanzar hacia ese desarrollo que parece, por fin, al alcance de todos? Este optimismo se percibe también al declarar la década de 1960 como el Decenio de Naciones Unidas para el Desarrollo, prolongado luego en un II Decenio de Naciones Unidas para el Desarrollo (década de 1970).

Peroya en los años 1970 se constata que esos esfuerzos no conducen a los resultados esperados porque, aunque es cierto que todos los países crecen económicamente, no todos lo hacen al mismo ritmo. Es más, como son los menos desarrollados lo que 
más lentamente crecen, las diferencias, lejos de reducirse, se están incrementando. Esta constatación obliga a reformular la pregunta inicial: ya no es ¿̇cómo crecer?, sino ¿̇por qué no nos es posible crecer como ellos?

Esta doble pregunta explica las dos grandes orientaciones en que se van a mover en estos años los teóricos de la naciente Economía Política del Desarrollo, unos más orientados a responder a la primera pregunta; otros, más a la segunda ${ }^{3}$.

A la primera pregunta se intentó responder desde la ortodoxia económica: el subdesarrollo es una cuestión temporal, de sociedades atrasadas, que deben entrar en un proceso de modernización económica, aumentando su producción y su renta. W. W. Rostow fue el principal representante de esta tendencia (Rostow, 1960). Los supuestos implícitos en esta orientación son dos: que el desarrollo se identifica con crecimiento económico; que está al alcance de todos, aunque el proceso se inicie y progrese a ritmos distintos en unos países y en otros.

La segunda orientación, que tiene un enfoque más heterodoxo, enfoca las cosas de forma muy diferente: el desarrollo de un país no puede explicarse ni promoverse sin tener en cuenta el escenario mundial donde este país se inserta. Y las relaciones que en ese marco se generan pueden hacer muy difícil o del todo imposible el desarrollo de esos pueblos. Esta orientación fue promovida desde la CEPAL ya en los años 1950 (Prebisch, 1963) y dio lugar después a la teoría de la dependencia que formula de forma más descarnada la situación: el subdesarrollo no es la fase previa al desarrollo, sino la consecuencia de este, porque el subdesarrollo de unos es lo que está haciendo posible el desarrollo de otros, en la medida en que estos últimos, a través de complejos mecanismos, se apropian de los excedentes de la producción. El mundo debe ser considerado, no como un conjunto de países autónomos, sino como un sistema único e interconectado.

Esta teoría de la dependencia, que alcanzaría gran difusión y muchos seguidores, se mantuvo dentro de la línea estructuralista en unos casos, pero adoptó en otros una inspiración marxista. La diferencia fundamental de esta última es que, para sus representantes, la salida del subdesarrollo es imposible dentro de una economía capitalista, por lo que solo vale el recurso a la revolución (Baran, 1957).

\footnotetext{
${ }^{3}$ Son diferentes los intentos de agrupar las distintas corrientes para la explicación del desarrollo, que incluyen propuestas políticas para alcanzarlo. El profesor Hidalgo-Capitán ha distinguido hasta siete (Hidalgo-Capitán, 2011). Nosotros seguiremos, de momento, el esquema más sencillo que propusimos en esta revista en un editorial de la misma (Consejo de Redacción, 2005), donde distinguíamos tres grandes tendencias: ortodoxas, heterodoxas y alternativas.
} 
Son muchos los autores que se ocuparon del tema, pero todos se podrían encajar en estas dos grandes orientaciones, que hemos llamado ortodoxa y heterodoxa. En todo caso, esta rápida visión de las principales líneas de la Economía Política del Desarrollo nos permitirá comprender mejor la aportación del PSC.

\section{I.2. El pensamiento social cristiano en el Concilio Vaticano II y en Pablo VI}

En estos años que estamos considerando se produjeron cambios de alcance en la Iglesia católica. Fue Juan XXIII, un papa con un breve pontificado (1958-1963), el que desencadenó un proceso que se venía gestando desde unas décadas antes. Y lo hizo con el anuncio, inesperado y que parecía superar sus posibilidades (por edad, etc.), de la celebración de un concilio ecuménico con el fin de la actualización de la Iglesia. Fue un proceso largo que Juan XXIII no pudo ver concluido puesto que se prolongaría hasta 1965. De hecho, de las cuatro sesiones conciliares celebradas, tres fueron ya presididas por el papa Pablo VI (que prolongaría su pontificado hasta 1978). Estos dos pontificados vienen a coincidir con el periodo que estamos considerando.

La renovación de la Iglesia asumida por el Concilio incluye abordar algunas de las cuestiones que más preocupaban entonces a la humanidad. Esta reflexión se había iniciado ya entre los cristianos, en el marco de la gran guerra recién concluida y en aquel ambiente de cierto optimismo que rodeó la reconstrucción. Entre estos temas se cuenta el de un nuevo orden mundial que impida el renacer de regímenes totalitarios, como los que provocaron la guerra, donde sea posible la convivencia para todos los pueblos, incluidos los recién constituidos como países independientes.

Esta preocupación por un orden mundial de convivencia para todos los pueblos está detrás de una de las primeras tareas que se impone la nueva Organización de las Naciones Unidas y que culminó en la Declaración Universal de los Derechos Humanos (1948). La Declaración constituía un marco normativo, que hacían suyos todos los países que se incorporaban a la ONU, por encima de cualquier voluntad soberana (el mejor antídoto para el totalitarismo). Hay que señalar que Pío XII, elegido papa unos meses antes de desatarse la contienda, tuvo este orden mundial como unos de los ejes de su pensamiento. Él lo concebía como un orden ético por encima de cualquier voluntad humana, algo que se buscó también con la Declaración Universal de los Derechos Humanos (1948), de la que incomprensiblemente nunca se hizo eco. Juan XXIII rompería ese silencio y basaría su encíclica sobre la paz (Pacem in terris), publicada unas semanas antes de su muerte, en los derechos humanos. Este texto podemos interpretarlo como un reencuentro entre el 
pensamiento moderno y la tradición cristiana actualizada por el papa: es cierto que en la fundamentación de los derechos había diferencias entre un texto y otro, pero el resultado viene a ser un conjunto de derechos que tiene no solo el mismo contenido, sino que son concebidos con idéntica función.

Este giro de Juan XXIII es sintomático de un cambio, después de dos siglos largos en que se ha vivido una etapa de desencuentro entre la Iglesia y el pensamiento moderno. Ahondar en esas vías de diálogo y reencuentro fue la tarea del Concilio. $Y$ entre ellas se encuentran las primeras manifestaciones sobre el desarrollo de los pueblos desde una óptica cristiana.

Lo vemos ya en la constitución GS, el último documento que el Concilio aprobó, quizá como exponente de la complejidad de las cuestiones que se querían abordar. De este documento podemos retener dos aportaciones: una antropología, una visión del desarrollo.

El PSC se ha desarrollado desde el siglo XIX en un ambiente muy particular: el debate con las grandes ideologías modernas, especialmente con el liberalismo y el comunismo marxista. Han sido muchos los temas de discusión. Pero quizás no se ha prestado la suficiente atención a lo que, en nuestra opinión, explica mejor las discrepancias: la concepción de la persona humana. Frente al individualismo liberal y al colectivismo marxista el pensamiento cristiano ha propuesto una visión de la persona como ser constitutivamente social, que ni puede entenderse como pura individualidad antes de entrar en relación con otros ni puede quedar diluido en la colectividad. Por citar un texto que sintetiza bien esta visión, véanse estas líneas de GS:

El principio, el sujeto y el fin de todas las instituciones sociales es y debe ser la persona humana, ya que por su propia naturaleza necesita absolutamente de la vida social (GS 25).

La sociedad toda se entiende en función de la persona, que se erige, no solo en centro y fin, sino también en sujeto activo (frente a concepciones paternalistas que sumen a la persona en la pasividad).

Esta antropología se complementa más adelante con la visión del auténtico desarrollo. Véase este pasaje como buena síntesis del pensamiento cristiano:

La finalidad fundamental de la producción, sin embargo, no es el mero aumento de los productos, ni el lucro o el poder, sino el servicio del hombre, y del hombre todo entero, sin perder de vista el ámbito de sus necesidades materiales ni las exigencias de su vida intelectual, moral, espiritual y religiosa, de cualquier hombre, decimos, y de cualquier grupo de hombres, no importa de qué raza o de qué región del mundo (GS 64). 
En pocas palabras, no hay desarrollo auténtico si no cumple dos condiciones: que sea de toda la persona (integral) y que alcance a todas las personas y a todos los pueblos (solidario). Este texto, leído en el contexto de los años 1960, no puede dejar de interpretarse como una crítica de un desarrollo centrado solo en el crecimiento económico, y una crítica un desarrollo que discrimina gravemente a los pueblos más atrasados.

Para valorar mejor esta propuesta hay que advertir que estamos ante un enfoque novedoso en los documentos oficiales del PSC desde sus comienzos en el siglo XIX. Estos siempre se habían centrado en los temas económicos y políticos, propios del debate con los sistemas capitalista y comunista. Ahora no se dejan de abordar esos mismos temas, pero se pone como criterio previo y determinante el desarrollo. Este enfoque pone en el centro a la persona, y es en función de ella como deben enjuiciarse las instituciones económicas y políticas. Va en la línea de lo indicado más arriba: es la antropología la que se va decantando como la clave de la aportación cristiana a los modos de organización de nuestras sociedades (Camacho, 2021).

Pablo VI se marcó como tarea central de su pontificado el concluir el Concilio y ponerlo en práctica. También lo hizo en el terreno del PSC. Se dice que, ya durante los años del Concilio, había concebido la idea de publicar un documento sobre el desarrollo, para lo que había ido recogiendo ideas y sugerencias. Y cumplió este propósito año y medio después con su encíclica PP (26 marzo 1967). Con él inaugura una nueva línea temática en los documentos oficiales, totalmente centrados hasta ahora en los problemas propios de las sociedades industriales avanzadas. Ahora interesa la humanidad entera y el desarrollo de todos,

muy especialmente el de aquellos que se esfuerzan por escapar del hambre, de la miseria, de las enfermedades endémicas, de la ignorancia; que buscan una más amplia participación en los frutos de la civilización (...); que se orientan con decisiónacia el pleno desarrollo (PP 1).

Toda la encíclica se articula en torno a dos ejes: desarrollo integral de la persona y desarrollo solidario de la humanidad. Ante la imposibilidad de entrar en un análisis exhaustivo de todo el texto, retendríamos las tres aportaciones que nos parecen más destacables en el contexto de aquellos años 1960: la definición del desarrollo, la responsabilidad de unos y otros, la crítica de los mercados internacionales.

La definición del desarrollo se busca, no solo en los técnicos, cada vez más necesarios, sino más todavía en "pensadores de reflexión profunda que busquen un humanismo nuevo, el cual permita al hombre moderno hallarse a sí mismo". Es sabido cómo Pablo VI sintonizaba con el filósofo francés Jacques Maritain (al 
que cita en este momento). Y continúa con esta "definición" tan expresiva de lo que significa el desarrollo para la persona, la cual es, afin de cuentas, el sujeto primordial del desarrollo:

Así podrá realizar en toda su plenitud el verdadero desarrollo, que es el paso para cada uno y para todos de condiciones de vida menos humanas a condiciones más humanas (PP 20).

La persona en el centro, no la sociedad o la producción económica. Y en el centro en un sentido dinámico: como un proceso que no tiene un término prefijado, y que se concreta en este párrafo, que en su extensión quiere expresar la complejidad de las variables que se incluyen:

Menos humanas: las carencias materiales de los que están privados del mínimum vital y las carencias morales de los que están mutilados por el egoísmo. Menos humanas: las estructuras opresoras que provienen del abuso del tener o del abuso del poder, de la explotación de los trabajadores o de la injusticia de las transacciones. Más humanas: el remontarse de la miseria a la posesión de lo necesario, la victoria sobre las calamidades sociales, la ampliación de los conocimientos, la adquisición de la cultura. Más humanas: el aumento en la consideración de la dignidad de los demás, la orientación hacia el espíritu de pobreza, la cooperación en el bien común, la voluntad de paz. Más humanas todavía: el reconocimiento por parte del hombre de los valores supremos y de Dios, que de ellos es la fuente y el fin. Más humanas por fin y especialmente: la fe, don de Dios acogido por la buena voluntad de los hombres y la unidad en la caridad de Cristo, que nos llama a todos a participar como hijos en la vida del Dios vivo, Padre de todos los hombres (PP 21).

Muchos comentarios suscitan estas líneas. Retengamos uno: la inserción de la dimensión religiosa y cristiana. Desde la perspectiva humanista de Pablo VI no es una alternativa, sino una culminación, que muestra adónde puede llegar el ser humano al trascender su propia realidad humana y abrirse a una realidad mayor, Dios en términos generales, Cristo como manifestación de Dios en la perspectiva cristiana.

Un segundo punto viene a terciar, al menos indirectamente, en la cuestión sobre en quién recae la responsabilidad del desarrollo de un pueblo. La respuesta es clara: en primer lugar, en el propio país en desarrollo, que tiene que adoptar una verdadera planificación (hay una clara opción por un modelo mixto de economía, donde la iniciativa privada debe ser encauzada desde los poderes públicos y donde no basta con crear riqueza sin la preocupación de distribuirla para que el desarrollo esté al servicio de todos, PP 32-34). Pero también los países desarrollados tienen una obligación de que los bienes de la creación, destinados a todos, no sean acumulados por unos pocos, sino que repercutan en todos (PP 48-49); y esto 
debe hacerse de una forma concertada, como sería el caso de "la constitución de un gran Fondo Mundial alimentado con una parte de los gastos militares, a fin de ayudar a los más desheredados" (PP 51).

Esto lleva a considerar el sistema del comercio mundial, a propósito del cual se hace una crítica contundente del modelo liberal:

Es decir que la regla del libre cambio no puede seguir rigiendo ella sola las relaciones internacionales. Sus ventajas son ciertamente evidentes cuando las partes no se encuentran en condiciones demasiado desiguales de potencia económica: es un estímulo del progreso y recompensa del esfuerzo. Por eso los países industrialmente desarrollados ven en ella una ley de justicia. Pero ya no es lo mismo cuando las condiciones son demasiado desiguales de país a país: los precios que se forman 'libremente' en el mercado pueden llevar consigo resultados no equitativos. Es, por consiguiente, el principio fundamental del liberalismo, como regla de los intercambios comerciales, el que está aquí en litigio (PP 58).

El texto es tan claro que apenas merece comentario: el mercado solo funciona de modo aceptable cuando se da igualdad entre las partes; en caso contrario, solo genera un incremento de las desigualdades. Estas observaciones críticas se mantienen en un terreno exclusivamente ético. Pero no puede negarse su sintonía con los mecanismos que analizaron los economistas de aquel tiempo para explicar las desigualdades: el deterioro de la relación real de intercambio (Prebisch, 1949), el imperialismo, la dependencia o la apropiación de excedentes.

Todavía en el pontificado de Pablo VI conviene reseñar una tercera aportación, ahora del documento sobre "La justicia en el mundo" del Sínodo Universal de Obispos de 1971. Interesa de él la referencia al derecho al desarrollo que, como veremos, será objeto de una Declaración solemne en la ONU en 1986. Aquí está ya formulado en unos términos que reencontraremos en la citada Declaración.

En efecto, al hacer el análisis de la situación mundial, tras 25 años de esperanzas que cada vez se ven más frustradas, el Sínodo denuncia "la desigual distribución que pone en manos de un tercio de la humanidad, es decir, de la que goza un mayor desarrollo, el control de tres cuartas partes de la renta, de las inversiones y del comercio", así como "la nueva percepción de los límites materiales de la biosfera". Ante todo esto, se mantiene viva una "aspiración a la justicia" que "se expresa también en la conciencia del derecho al desarrollo". El contenido de este derecho se formula así:

Este derecho ha de ser visto en la interpenetración dinámica de todos aquellos derechos fundamentales humanos en que se basan las aspiraciones de los individuos y de las naciones. 
Es una definición de interés porque de nuevo concentra el desarrollo en la persona, que es el sujeto de todos los derechos humanos. Y subraya al mismo tiempo cómo los derechos son indivisibles, lo que se expresa bien en la fórmula que viene como a sintetizarlos todos: el derecho al desarrollo.

\section{I.3. El desarrollo como tema ético}

En el primer apartado de esta parte hablamos de economistas teóricos, dentro de la Economía Política del Desarrollo. Ahora nos toca avanzar sobre eso para destacar cómo en los temas arriba mencionados se pueden adivinar ciertos implícitos que abren el espacio a la reflexión ética, que algunos autores van pronto a trabajar y profundizar. Detrás de la cuestión de los economistas jcómo conseguir el desarrollo? uno puede formular otras preguntas: ¿qqué se entiende por desarrollo?, ¿̇uáles son los objetivos que se pretenden alcanzar con las políticas de desarrollo? Las respuestas no derivan solo del análisis científico, sino de otros ingredientes que a veces se dan por demasiado obvios. Tocamos aquí la siempre controvertida cuestión de la objetividad del análisis científico: ¿̇no hay presupuestos en el análisis que suponen juicios de valor? (Cortina, 2019, pp. 105-108).

Siempre se reconoce a Denis Goulet (1931-2006) como el iniciador y el padre de la ética del desarrollo. Goulet llega a sus elaboraciones más teóricas después de sus estudios de filosofía y teología, cuando vivió la realidad de pobreza y la marginación en Francia, España, Argelia, Líbano y otros países. El contacto con esa realidad le lleva a preguntarse cómo la gente en unas determinadas circunstancias piensa y busca el sentido del mundo y de las opciones que se le presentan, contando con las fuerzas de que cada uno dispone.

Sus ideas no llega a sistematizarlas sino en 1995, pero ya en 1960 publica un artículo que viene a ser como el manifiesto de una ética práctica de desarrollo (Gasper, 2008). Goulet se sorprende de que la ética no haya entrado en el campo del desarrollo, cuestiona la falta de criterios de los políticos a la hora de promover el desarrollo, denuncia los grandes desequilibrios entre países desarrollados y menos desarrollados, critica falsos desarrollos centrados en la acumulación de la riqueza y el aumento de los bienes solo materiales. Se sorprende, en suma, de un enfoque

que solo reconociera los valores medibles en términos monetarios y no dudase incluso en 'materializar' al hombre tratándolo como simple instrumento de producción, unidad de consumo, votante o portador de armas (Goulet, 1960). 
Pero lo más destacable es la propuesta que hace de lo que debe ser el desarrollo, que presenta como el nuevo nombre que hay que dar al concepto ético tradicional de "bien común". En palabras de Goulet el desarrollo debería consistir en

ordenar por etapas las condiciones globales que permitan al hombre, como individuo y como miembro de un grupo, pasar a un modo de vida más humano que el anterior -y esto, lo más rápidamente posible y con el menor coste (Goulet, 1960).

Posteriormente sintetizaría Goulet los dos grandes principios estratégicos del desarrollo así: tener lo suficiente para ser más, solidaridad universal (Goulet, 1999, 67-78).

Evidentemente estas ideas en germen las desarrollará más tarde, ya en el ámbito académico en que se movió la segunda parte de su vida. Ahora bien, para comprender mejor esta aportación de Goulet hay que acercarnos un poco más al ambiente de la primera etapa de su vida e identificar a quien fue su mentor, el dominico Lovis-Joseph Lebret(1897-1966), al que dedica una semblanza cargada de admiración. Lebret consagró toda su vida a tareas sociales, desde sus primeros trabajos con los marineros de la costa bretona, su región de origen. Pronto se sintió interpelado por la miseria de que se veía rodeado. Y eso le llevó a poner a punto un método de encuesta para definir mejor las carencias de las realidades en que vivía, método que aplicó en varios países. Vuelto a Francia durante la segunda guerra mundial, aprovechó ese tiempo para rodearse de un grupo expertos y para crear poco después, en 1941, un centro de investigación interdisciplinar para trabajar en todo lo relacionado con una economía más humana: Économie et Humanisme (Équipe d'Économie et Humanisme, 1966). A partir de ahí dedicó la última etapa de su vida a colaborar con los países en desarrollo de América Latina y África dirigiendo estudios y proyectos para su desarrollo.

Fruto de esta larga experiencia fue su principal obra Dinámica concreta del desarrollo (Lebret, 1961). Poco después Lebret fue llamado a Roma como experto para participar en el Concilio Vaticano II, concretamente en la redacción de GS (Hovée, 1997, pp. 174-184). Y, concluido el Concilio, Pablo VI le encomendó personalmente la composición de la nueva encíclica que quería publicar, PP, que ya hemos analizado. El libro donde Lebret sintetiza las conclusiones de treinta años de investigación y de experiencia (Lebret, 1961, p. 7) merece un momento de atención. Quiere proponer una "dinámica concreta" del desarrollo que centra en la tensión necesidad-posibilidad; pero ello supone un concepto de desarrollo en que lo que cuenta es el hombre. Esta puede ser la aportación más fundamental de Lebret, que se perfila ya cuando distingue dos conceptos de desarrollo: uno mecanicista (aumentar la producción) frente a otro orgánico (que consiste en la 
elevación humana en todas las capas de la población). Se contrapone así una economía que tiene valor en sí misma a una economía humana "que valga para todo el hombre y para todos los hombres" (Lebret, 1961, p. 39). Esta economía que Lebret llama humana se define así:

La economía humana es para nosotros, como ciencia y como técnica, la disciplina de las transiciones en una evolución ordenada, para una población o subpoblación determinada, de una fase menos humana a una fase más humana, al ritmo más rápido y al coste menos elevado posible, teniendo en cuenta la solidaridad entre las subpoblaciones y las poblaciones (Lebret, 1961, p. 40).

Reconocemos en este pasaje lo que ya encontramos en PP. Pero ahora con una insistencia más explícita en lo esencial del desarrollo: que esté centrado en el hombre, no en los niveles de producción. Para Lebret, los principios en que se apoya el desarrollo son dos: el respeto activo a toda persona humana (para que cada uno pueda tener más y ser más), que la convierte en sujeto y protagonista de su propio desarrollo; y el deseo del bien común (para asegurar el valor más universal) (Lebret, 1961, pp. 41-42).

La sintonía entre Denis Goulet y el P. Lebret es muy fuerte. El primero reconoce el carácter pionero del dominico en este campo y deplora que no le haya sido reconocido entre los expertos en desarrollo internacional. Alaba en él su síntesis entre lo ético cristiano y lo técnico, de modo que no rehúye hablar de profecía, de compromiso o de amor. Porque es esencial conjugar inteligencia y amor, para huir de la tecnocracia embrutecedora y del amateurismo. Y es que los males estructurales crónicos no se pueden corregir con solo buena voluntad y sin hacer un análisis riguroso de cómo estas estructuras funcionan. Ese carácter pionero de la obra de Lebret lo sintetiza en varios puntos: el desarrollo exige nuevos valores y una nueva civilización a insertar donde la mayoría de las instituciones existentes contradicen las aspiraciones humanas; el camino para ello es buscar el crecimiento optimo teniendo en cuenta los valores de la población y la limitación de los recursos; la planificación es inútil si no existe una colaboración permanente entre quienes deciden desde arriba y las comunidades en la base; la equidad en la distribución de la riqueza y la atención a los derechos de todos son los objetivos prioritarios de todo desarrollo; los conflictos de intereses solo pueden superarse eliminando privilegios y abordando una pedagogía general de la austeridad (Goulet, 1974, pp. 55-56). 


\section{El último tercio del siglo $X X$ : el desarrollo en un mundo globalizado - La aportación del papa Juan Pablo II}

Entramos en una nueva etapa, cuyos comienzos vienen marcados por la crisis económica mundial que sucedió a la fase expansiva en que nos habíamos movido hasta ahora y que tiene como dos momentos que expresan que estamos entrando en una fase nueva: el primero fue la crisis del sistema monetario internacional nacido de los acuerdos de Bretton Woods que desemboca en la decisión del presidente norteamericano Richard Nixon de suspender unilateralmente la convertibilidad del dólar (1971); el segundo fue la decisión de los países de la OPEP de subir drásticamente los precios de los crudos petrolíferos (en 1973-1974, y de nuevo en 1979). Este nuevo escenario, que nos encamina a la caída del muro de Berlín y al final de un mundo dividido en bloques, afecta naturalmente a las ideas y las políticas relacionadas con el desarrollo.

\section{I. La confrontación entre la escuela neoliberal y las teorías alternativas del desarrollo}

El liberalismo va a renacer como una crítica al modelo de Estado intervencionista, por convertirse en un freno para el funcionamiento del libre mercado. Es cierto que el modelo de Estado social, con unos poderes públicos muy activos en la organización y dirección de la economía está en el origen del progreso considerable de los países más avanzados. Pero este modelo comenzará pronto a dar síntomas de agotamiento. Y especialmente es objeto de críticas en los países en desarrollo, que han evolucionado hacia regímenes paternalistas (de orientación populista) paralizadores de la iniciativa privada, muchos de ellos atenazados por el fortísimo incremento de la deuda externa ${ }^{4}$.

Economistas liberales procedentes de los grandes centros universitarios del mundo anglosajón irrumpieron en agencias estatales de algunos países así como en organismos internacionales para poner en práctica sus ideas. Propugnan una decidida liberalización interna, reduciendo el papel del Estado para permitir al mercado funcionar con las menores trabas posibles y garantizar así la libre competencia. Y propugnan también una no menos decidida liberalización externa para aprovechar las ventajas comparativas derivadas del comercio internacional y de las inversiones extranjeras. Se suponía que esta liberalización terminaría distribuyéndose entre

${ }^{4}$ La alarma saltó cuando algunos de los países más fuertemente endeudados en América Latina (México, Brasil y Argentina) se declararon insolventes a finales de 1982. 
todos los sectores de la población gracias a los mecanismos del mercado (Hidalgo-Capitán, 2011 , pp. 296-299).

Este modelo neoliberal, que fue aplicado con rigor en el Chile de Pinochet (por los llamados "Chicago boys") durante los años en que fue presidente de la República (1974-1990), contó además con el apoyo de nuevos líderes mundiales significados, como Margaret Tatcher (primera ministra del Reino Unido entre 1979 y 1990) o Ronald Reagan (presidente de los Estados Unidos, 1981-1989). Esta orientación neoliberal inspiró las políticas que se aplicaron a otros países latinoamericanos para superar el problema generado por la deuda externa: se trataba de duras políticas de estabilización macroeconómica y de ajuste estructural, que además venían impuestas por los organismos económicos internacionales (FMl y Banco Mundial) como condición para prestar ayuda. Todo ello se recogió en 1990 en el llamado Consenso de Washington, sintetizado por John Williamson en un documento que sistematizaba lo que había sido la práctica dominante en aquellos años. El documento, que hemos consultado reproducido en una obra posterior (Williamson 2002), aclara que con la referencia a Washington se quiere aludir a lo que en aquella ciudad se desea (en el Congreso y en la Administración, y también en los ámbitos tecnocráticos de las instituciones financieras, como la Reserva Federal) como un conjunto apropiado de reformas de política económica. Se identifican hasta diez propuestas, que son solo instrumentos de política, porque los objetivos se dan por supuestos y evidentes: crecimiento, baja inflación, equilibrio en la balanza de pagos y una equitativa distribución de la renta. Este dar por buenos unos objetivos nos devuelve a la etapa en que no parecía necesario mostrar al servicio de quien se pone el desarrollo: Pero estamos lejos de un desarrollo centrado en la persona humana; más aún, el objetivo de la equidad, aunque mencionado, queda prácticamente excluido entre las medidas (Mària, 2000).

Los resultados de estas políticas fueron muy negativos para la mayoría de los países de América latina y, sobre todo, para los del África Subsahariana. El mismo Banco Mundial reconoce en su informe sobre el desarrollo de 1990 (que dedica a la pobreza en el mundo) que la década que termina puede ser considerada como la década perdida para esos pueblos: el nivel de vida en América Latina ha caído para la mayoría por debajo del de los años 1970, y en África subsahariana por debajo del de los años 1960 (World Bank, 1990, p. 7).

La constatación de todo esto explica que, frente a estas visiones ortodoxas del desarrollo, surgiera una línea crítica, que podemos englobar bajo la denominación de teorías alternativas (Consejo de Redacción, 2005, pp. 19-21). Un rasgo que identifica a estas teorías es el poner en el centro a la persona: el criterio decisivo 
para un modelo de desarrollo es que se coloque decididamente al servicio del ser humano. Se trata de "otro desarrollo", un enfoque más microeconómico que macroeconómico, que se orienta no tanto a aumentar la riqueza y la renta cuanto a reducir la pobreza (Hidalgo-Capitán, 2011, pp. 302-303). Y para ello nada tan eficaz como satisfacer las necesidades básicas de cada persona capacitándolas para que tengan acceso real a los recursos que les permitan esa satisfacción.

Dentro de esta corriente de desarrollo alternativo se pueden encuadrar líneas distintas: desarrollo humano, desarrollo territorial, desarrollo sostenible, desarrollo con perspectiva de género, post-desarrollo, etc. Más que entrar en el detalle de cada uno ahora, intentaremos más abajo destacar los contenidos éticos que pueden descubrirse en ellos.

\subsection{El pensamiento social cristiano de Juan Pablo II}

El pontificado de Juan Pablo Il se cuenta entre los más largos de la historia (19782005). La personalidad y el pensamiento del polaco Karol Woityla están muy condicionados por su procedencia y los años que vivió bajo régimen comunista. Hasta ahora el PSC, sobre todo en los documentos oficiales, había reflexionado sobre la confrontación entre los dos grandes sistemas de la época moderna desde el interior de uno de ellos, el capitalismo occidental. Juan Pablo II fue el primero que lo hizo desde su experiencia en país comunista: antes de 1989, buscando vías para una superación de las principales deficiencias del comunismo y evitando las condenas menos matizadas de algunos de sus predecesores; después de 1989, analizando las razones del fracaso del colectivismo y el futuro de un mundo sin más opción que el capitalismo (Camacho, 1998, pp. 481-485).

En su extenso pontificado se ocupó también Juan Pablo II del desarrollo. Pero antes de abordar esa cuestión merece destacarse el enfoque del PSC que parece consolidarse con el papa polaco. En su nivel más profundo, de nuevo nos encontramos con la visión del hombre y sus consecuencias para la organización de la sociedad. Este es el punto en que Juan Pablo II discrepa tanto del liberalismo como del marxismo, las dos grandes ideologías de los tiempos modernos (Camacho, 2005, pp. 206-207).

Este distanciamiento respecto a una y otra ideología aparece en la encíclica sobre el desarrollo: Encíclica Sollicitudo rei socialis, al cumplirse el vigésimo aniversario de la Populorom Progressio (1987, en adelante SRS). Sus aportaciones a una ética del desarrollo pueden sintetizarse en cuatro puntos. 
La primera aportación, que es como una cuestión previa, es la reafirmación del carácter ético del desarrollo, que no puede reducirse a algo meramente técnico, ni tampoco a una confianza en el progreso ilimitado de la humanidad como un proceso automático (SRS 27). Entra en juego la acción humana y, por eso, la dimensión ética que ayuda a establecer los fines del desarrollo y los medios. Esta afirmación le sirve para puntualizar cuál es el papel de la lglesia en este campo: no tanto elaborar propuestas técnicas cuanto iluminar el alcance ético del tema desde la visión cristiana de la persona humana y de la sociedad (SRS 41). Esta visión será la que inspirará después a muchos cristianos que sí llegarán a implicarse en propuestas y proyectos concretos (el caso de Lebret es relevante).

Una segunda aportación tiene que ver con el análisis de las causas de lo que la encíclica denuncia: el contraste "desconcertante" entre las miserias del subdesarrollo y esa especie de superdesarrollo de una buena parte de la humanidad (SRS 28). Según la lectura hecha por Juan Pablo II -y esta lectura, anterior a los acontecimientos de 1989, no sería aceptada por muchos especialistas-, la raíz última había que buscarla en la división del mundo en dos grandes bloques y en las ideologías que los sustentaban ${ }^{5}$. Se puede discutir si este análisis era correcto, pero lo que queda claro una vez más es la importancia del nivel antropológico para comprender donde el pensamiento cristiano toma distancia crítica.

La tercera aportación se refiere a la concepción misma del desarrollo. De entrada se excluye que este pueda reducirse a desarrollo económico (SRS 9) porque la "la mera acumulación de bienes y servicios, incluso en favor de una mayoría, no basta para proporcionar la felicidad humana" (SRS 28). El verdadero desarrollo consiste en una adecuada relación entre el "tener" y el "ser" que se expresa bien en la contraposición de estos dos extremos:

están aquéllos -los pocos que poseen mucho- que no llegan verdaderamente a 'ser', porque, por una inversión de la jerarquía de los valores, se encuentran impedidos por el culto del 'tener'; y están los otros -los muchos que poseen poco o nada- los cuales no consiguen realizar su vocación humana fundamental al carecer de los bienes indispensables (SRS 28).

5 En Occidente existe, en efecto, un sistema inspirado históricamente en el capitalismo liberal, tal como se desarrolló en el siglo pasado; en Oriente se da un sistema inspirado en el colectivismo marxista, que nació de la interpretación de la condición de la clase proletaria, realizada a la luz de una peculiar lectura de la historia. Cada una de estas dos ideologías, al hacer referencia a dos visiones tan diversas del hombre, de su libertad y de su cometido social, ha propuesto y promueve, bajo el aspecto económico, unas formas antitéticas de organización del trabajo y de estructuras de la propiedad, especialmente en lo referente a los llamados medios de producción (SRS 20). 
El último referente es, entonces, esta "vocación humana fundamental", quizás algo imprecisa pero que remite evidentemente más allá de lo material y sugiere el ámbito de lo más personal del sujeto. Tendremos ocasión de precisarlo.

Esta explicación del auténtico desarrollo se circunscribe a un discurso de carácter ético-filosófico. Pero SRS añade un enfoque más teológico, que es complementario. Lo vincula con la relación entre el ser humano y Dios: porque desde una perspectiva creyente el ser humano procede de Dios (creación) y está destinado a un encuentro pleno y definitivo con él (SRS 30-31). El desarrollo humano se inserta, entonces, en este proceso, donde el creyente se vive a sí mismo con el encargo de continuar la obra de la creación que Dios inició. Es una lectura creyente de toda la vida humana como proceso, que no añade contenidos nuevos, pero sí otra motivación que refuerza el compromiso ético en pro de un desarrollo personal y social.

Una última contribución se centra en la solidaridad, término que ha quedado como el más representativo de toda la encíclica del papa polaco. La solidaridad es la mejor respuesta ética a un mundo cada vez más interdependiente (hoy diríamos globalizado). ¿Cómo entender esta solidaridad?

Esta no es, pues, un sentimiento superficial por los males de tantas personas, cercanas o lejanas. Al contrario, es la determinación firme y perseverante de empeñarse por el bien común; es decir, por el bien de todos y cada uno, para que todos seamos verdaderamente responsables de todos (SRS 38).

Frente a las solidaridades "blandas", que son más bien "tranquilizantes de conciencia", aquí se apuesta por un ser efectivamente "todos responsables de todos".

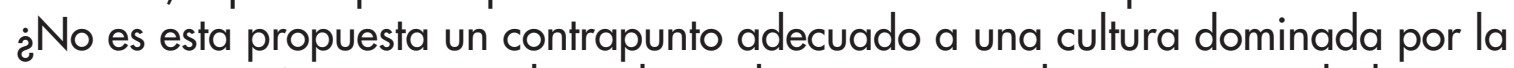
competencia? No es negar los valores de esta, pero sí limitar y contrabalancear esa tendencia a vivir al otro siempre como un potencial enemigo (en el sentido de que nos disputa aquello a lo que legítimamente aspiramos). ¿ No subyace aquí una antropología que se distancia de los valores dominantes en nuestra sociedad? Porque, si concebimos el mundo solo en términos de competencia, ¿̇no estamos abocados a sociedades cada vez más desiguales?

\subsection{El desarrollo como tema ético}

Si más arriba nos referimos a la contraposición entre teorías ortodoxas y teorías heterodoxas sobre el desarrollo, en la época que ahora estamos estudiando asistimos a un fuerte impulso de las teorías alternativas (Consejo de Redacción, 2005, pp. 19-21; Hidalgo-Capitán, 1998, pp. 193-232). Nos interesa mencionarlas 
aquí porque tienen un más explícito contenido ético. Estas teorías empiezan a inspirar además iniciativas en el campo económico y social. En esta nueva línea de avance destacaríamos tres elementos: la Declaración del derecho al desarrollo y los conceptos de desarrollo sostenible y de desarrollo humano.

El derecho al desarrollo empieza siendo concebido y reivindicado con un derecho colectivo, en el marco de una nueva disciplina, el Derecho Internacional del Desarrollo y la regulación de las relaciones entre Estados jurídicamente iguales, pero económicamente desiguales. Hay que esperar a 1972 para que Keba M'Baye, Primer Presidente de la Corte Suprema de Senegal, hable de un "derecho del hombre". Para él. los derechos colectivos son derechos individuales que, para ser puestos en práctica, precisan del acuerdo de varias voluntades.

Con estos precedentes llegamos a 1986, cuando la Asamblea General de la ONU aprueba, tras largos años de gestación, la Declaración del Derecho al Desarrollo. Lo entiende como un derecho individual y colectivo a la vez. Pero, ante todo, es un derecho de la persona: "La persona humana es el sujeto central del desarrollo y debe ser el participante activo y el beneficiario del derecho al desarrollo" (art. $2,1)$. Destaca no solo la prioridad de la persona, sino también el considerar a esta como sujeto activo en su realización, y no solo beneficiario.

¿Cuál es su alcance? Se presenta como un derecho que, de alguna forma, engloba a todos los demás derechos ${ }^{6}$. Y este carácter globalizante, que para algunos juristas es fuente de dificultades para aceptarlo como un verdadero derecho, es exponente para otros de un derecho que remite a la autorrealización humana como el núcleo de todos los derechos, que serían como instrumentos para su realización (Kooijmans, 1990), o como expresión de la interdependencia e indivisibilidad de los derechos humanos (Cançado, 1990). En todo caso, el derecho al desarrollo ha servido para poner en relación el desarrollo con los derechos humanos, lo que subraya más aún la centralidad de la persona al concebir el desarrollo.

Si queremos fijar una fecha significativa para el reconocimiento del desarrollo sostenible es obligado referirse al Informe Brundtland (1987) y a la Conferencia de Río de Janeiro sobre Medio Ambiente y Desarrollo (1992). El primero forma parte de la preparación de la segunda: de ahí su estrecha relación.

El Informe Brundtland fue realizado por una comisión liderada por la entonces primera ministra norvega, Gro Harlem Brundtland, tomando como punto de partida

"Recuérdese la definición del Sínodo de 1971, que hablaba de la "interpenetración". 
la relación entre la población pobre y vulnerable y el deterioro del medio ambiente. Si el desarrollo de estos colectivos -tan deseado, por otra parte- amenaza al medio ambiente, es preciso buscar un equilibrio, que el citado informe concreta en el concepto de desarrollo sostenible, y que queda definido así:

Está en manos de la humanidad hacer que el desarrollo sea sostenible, es decir, asegurar que satisfaga las necesidades del presente sin comprometer la capacidad de las futuras generaciones para satisfacer las propias (Comisión Mundial del Medio Ambiente y Desarrollo, 1988, p. 29).

El Informe plantea ya la cuestión más radical que deriva del concepto de desarrollo sostenible: la imposibilidad de universalizar el modelo de desarrollo de los países avanzados con sus altos niveles de consumo. El planeta no tiene capacidad para responder con sus recursos. Hay aquí una cuestión de justicia y equidad: si queremos desarrollo para todos y desarrollo sostenible, los estándares de consumo de los países más ricos deben ser sometidos a revisión.

Esta relación estrecha entre medio ambiente y desarrollo será el tema central de la Conferencia de Río de Janeiro de 1992. Su declaración final, Declaración sobre el medio ambiente y el desarrollo, deja claro en su Principio 1 la ya conocida apuesta por el ser humano como referente fundamental: "Los seres humanos constituyen el centro de las preocupaciones relacionadas con el desarrollo sostenible. Tienen derecho a una vida saludable y productiva en armonía con la naturaleza". La Declaración abunda en la necesidad de combinar el derecho de los Estados a disponer de sus recursos naturales con la responsabilidad en un uso de ellos que no atente contra la sostenibilidad del planeta.

Esta centralidad del ser humano nos lleva al concepto de desarrollo humano, que hay que vincular con el Programa de Naciones Unidas sobre el Desarrollo (PNUD). Este organismo, creado en 1965 para contribuir al desarrollo de los pueblos, viene publicando un informe anual desde 1990. Y ha sido en ese documento donde ha puesto en circulación el concepto de desarrollo humano.

Se sitúa en continuidad con el Ajuste con rostro humano, un texto promovido por UNICEF como alternativa al ajuste estructural de que ya hemos hablado: en él se reconocía que el ajuste había que hacerlo, pero garantizando a los grupos más vulnerables la cobertura de sus necesidades básicas en cuanto a alimentación, educación y salud.

Desarrollo humano nos recuerda el desarrollo integral del Concilio Vaticano II. La intuición de fondo es la misma. De hecho, ya el Informe de 1990 deja claro desde el comienzo como 
la reciente experiencia en desarrollo es un recordatorio poderoso de que la expansión de la producción y la riqueza es sólo un medio (PNUD, 1990, p. 33).

$Y$ en seguida se precisa:

El desarrollo humano es un proceso en el cual se amplian las oportunidades del ser humano. En principio, estas oportunidades pueden ser infinitas y cambiar con el tiempo. Sin embargo, a todos los niveles de desarrollo, las tres más esenciales son disfrutar de una vida prolongada y saludable, adquirir conocimientos y tener acceso a los recursos necesarios para lograr un nivel de vida decente. Si no se poseen estas oportunidades esenciales, muchas otras alternativas continuarán siendo inaccesibles (PNUD, 1990, p. 34).

No cabe duda que se consolida así un enfoque nuevo del desarrollo: centrado en la persona, sí, pero además considerando a esta no solo como destinataria sino como agente activo de su propia existencia. Por eso se trata de dotarla de las condiciones que le permitan progresar según sus aspiraciones.

Un paso ulterior exige dotarse de instrumentos para hacerlo operativo en su aplicación a las políticas concretas. Este instrumento va a ser el Índice del Desarrollo Humano, que el PNUD va a elaborar para sustituir al indicador hasta ahora empleado, el PIB per cápita.

Para completar este giro tan significativo que representa el desarrollo humano hay que mencionar a uno de sus principales inspiradores: el indio Amartya Sen, Premio Nobel de Economía (en 1998). El título de una de sus obras más señaladas expresa sintéticamente su idea de desarrollo: Desarrollo es libertad. Y explica su contenido recurriendo a dos conceptos no siempre fáciles de entender: funcionamiento (functioning), que es lo que las personas valoran ser o hacer; capacidad (capability) o libertad que tiene una persona efectivamente para disfrutar de eso que valora ser o hacer porque contribuye a su bienestar. El desarrollo consiste en tener la libertad para hacer realidad aquello a lo que uno aspira. Ello implica eliminar las principales fuentes de privación de libertad, como son la pobreza y la tiranía, la escasez de recursos económicos, el abandono de los servicios públicos, etc. (Sen, 2000, 19-28). Sen no quiere descender hasta fijar el contenido de lo que es bueno para las personas; se queda en ese dotarlas de condiciones mínimas para que cada una haga luego realidad sus aspiraciones ${ }^{7}$. Esas condi-

\footnotetext{
${ }^{7}$ En esto se va a diferenciar Martha Nussbaum de Amartya Sen. Ella va a intentar definir lo que serían unas capacidades básicas (diez llega a identificar) que la sociedad debería garantizar a todos. Uno y otro se basan en la filosofía política de John Rawls y en su idea de un "pluralismo razonable", que se propone transformar estas capacidades en metas específicamente políticas, y no quedarse en el mero reconocimiento de unos derechos (Colmenarejo, 2016).
} 
ciones son una salud aceptable, una mejor educación y un cierto nivel de renta, precisamente lo que el Índice de Desarrollo Humano se encarga de cuantificar. Es claro que para Sen el desarrollo se centra en la persona y no en los bienes de que pueda disponer.

Entre los precedentes directos de estos conceptos suelen citarse el "enfoque de las necesidades básicas", que ya formulara la Organización Internacional el Trabajo en 1974 y la propuesta de "otro desarrollo" de la Fundación Dag Hammarskiöld (1975).

\section{El siglo XXI: globalización y cuidado de la casa común - Las aportaciones de Benedicto XVI y de Francisco}

El siglo actual tiene como dos coordenadas que se consolidan. Por una parte, la globalización como interdependencia de todos los pueblos, que nos hace vivir con una conciencia creciente de que formamos una gran familia, al menos en cuanto que tenemos un destino común. Por otra parte, la incorporación de la perspectiva ecológica: el desarrollo de la humanidad no puede pensarse al margen del medio ambiente, no solo como recurso compartido sino también como hogar que nos acoge, como casa común. Y la perspectiva ecológica ha hecho más acuciante la pregunta sobre los límites del desarrollo dando lugar a propuestas alternativas centradas en el decrecimiento.

\section{I. El desarrollo sostenible en un mundo globalizado}

La globalización es un fenómeno irreversible en cuanto "integración más estrecha de los países y de los pueblos del mundo, producida por la enorme reducción de los costes de transporte y comunicación, y el desmantelamiento de las barreras artificiales a los flujos de bienes, servicios, capitales, conocimientos y (en menor grado) personas a través de las fronteras" (Stiglitz, 2002, 34). Si la globalización se manifiesta, al menos en principio, como un fenómeno económico, hay que añadir en seguida que tiene consecuencias políticas y culturales.

Económicamente hablando la globalización nos conduce hacia un mercado único mundial, donde se reproducen los mismos problemas de todo mercado: que la desigualdad inicial de las partes se reproduce e incrementa cuando estas actúan con libertad y con las mínimas cortapisas impuestas por el poder establecido. Y 
esto nos lleva, más allá de la dimensión económica, a las consecuencias políticas de la globalización: los Estados nacionales encuentran cada vez más dificultades para realizar su función esencial de ser la forma última de organización política y social. Y es que el marco que hacía posible desarrollar sus acciones, las fronteras territoriales, cada vez tienen menos vigor y entidad. No es que el Estado nacional haya desaparecido, ni es previsible que desaparezca a corto plazo. Pero ahora el escenario es distinto: un mercado crecientemente unificado donde compiten las grandes empresas y los mismos Estados, cada uno en función del poder que realmente tienen. Por eso "la globalización tiene ganadores y perdedores" (PNUD, 1997 , p. 92). ¿ Hay posibilidad de que una instancia supraestatal con competencia a escala planetaria establezca unas reglas de juego y tenga capacidad efectiva para exigir su cumplimiento (como hizo en Estado nacional con el paso de un modelo de capitalismo liberal a un capitalismo mixto)?

En este mercado único también la cultura se globaliza en la medida en que se homogeneiza y-¿por qué no decirlo?- se occidentaliza. La difusión de esta economía globalizada, que tiene su origen en los países occidentales, sirve como de vehículo a todo un conjunto de usos y costumbres, de valores, que se van haciendo dominantes.

Los avances tecnológicos que han hecho posible la globalización hacen pensar que el proceso no tiene vuelta a atrás. Pero no estamos ante un proceso que se desarrolle de forma mecánica, sino que ha avanzado según los intereses de las grandes potencias políticas y económicas ${ }^{8}$.

En este escenario comienzan a adquirir un protagonismo nuevo los organismos supraestatales, ya sean formados espontáneamente por países que se agrupan, ya sean formalmente constituidos. Entre los primeros se cuenta el $G-20$, que no es sino una ampliación del G-7, pero ahora ofreciendo un rostro más plural que refleja mejor la diversidad del planeta. Entre los segundos merece atención la ONU por las nuevas funciones que asume, como ha quedado de manifiesto en los acuerdos que han llevado a los Objetivos de Desarrollo Sostenible.

8 Ya lo denunciaba el propio PNUD: "Los principios de los mercados mundiales libres, sin embargo, se aplican de manera selectiva. Si así no fuera, el mercado mundial de mano de obra sin calificar sería tan libre como el mercado de las exportaciones o los capitales de los países industrializados. Las negociaciones mundiales avanzan rápidamente hacia un mercado mundial libre en inversiones y servicios extranjeros. Pero la intervención en la agricultura y los textiles sigue siendo elevada, lo que constituye un obstáculo para los países en desarrollo. Carentes de poder, con demasiada frecuencia se descuidan y socavan los intereses de los países pobres y de los pueblos pobres" (PNUD, 1997, p. 92). 
Es importante comprender los cambios de enfoque que se han producido desde que comenzó a indagarse cómo los países atrasados podrían alcanzar los niveles de desarrollo logrados ya por los países avanzados. La pregunta por el cómo se ha transformado en una pregunta por el qué. Y esta pregunta afecta ya no solo a los primeros sino a los segundos. Y los afecta en dos sentidos: no solo es un problema de viabilidad (¿̇podrá el planeta con sus recursos limitados soportar un desarrollo con un nivel de consumo de todos equivalente al de los pueblos más ricos?), es además un problema de justicia (¿̇es justa una distribución de los recursos que permita el desarrollo de unos exigiendo que otros renuncien a ello porque no habría recursos para todos?). Todo ello lleva indefectiblemente a comprender que el problema del desarrollo no es solo de los pobres, sino de todos: la pregunta sobre qué desarrollo deseamos no solo tendría que orientar las políiticas de los más atrasados; cuestiona además el estilo de vida de los más ricos. Este es el sentido que tienen las teorías del decrecimiento, que vienen encontrando un eco considerable ya en el siglo XXI.

El francés Serge Latouche es suficientemente representativo de esta línea de pensamiento como para que nos detengamos unos momentos en sus propuestas. Su obra nace y se elabora en el Norte opulento en la etapa en que se perciben los efectos de la crisis que se iniciara en los años 1970. La crisis ha puesto de manifiesto que el crecimiento económico ha traído desde entonces más costes que beneficios. La obra de Letouche es, ante todo, una crítica del crecimiento económico, pero no de todo crecimiento económico, sino de aquel que se ha producido en ese Norte opulento, un crecimiento basado en el consumo desenfrenado, cuyos pilares son tres: la publicidad (que crea el deseo de consumir), el crédito (que facilita los medios) y la caducidad (que renueva la necesidad) (Latouche, 2009, pp. 26-30).

Latouche no se queda en la crítica, propone un programa que sintetiza en las ocho " $R$ ": revaluar, reconceptualizar, reestructurar, redistribuir, relocalizar, reducir, reutilizar, reciclar. Y subraya cómo tres de ellas tienen un papel estratégico: reducir condensa todos los imperativos; relocalizar supone recuperar lo local y hacer de ello el lugar de la actividad económica siempre que se pueda, también de la vida cultural y política; revaluar consiste en el cambio de valores, que es la base y el motor de todo?. Es un programa que va más allá del capitalismo en todas

9 Este cambio es ambicioso:

El altruismo debe dar un paso frente al egoísmo, la cooperación frente a la competencia desenfrenada, el placer del goce y el ethos del juego frente a la obsesión del trabajo, la importancia de la vida frente al consumo ilimitado, lo local frente a lo global, la autonomía frente a la heteronomía, 
sus variantes y del socialismo actual, porque ambos tienen el mismo proyecto de sociedad de crecimiento basado en el desarrollo de las fuerzas productivas que se suponen son las fuentes del progreso (Latouche, 2009, p. 113).

Estamos lejos de los enfoques iniciales, pero hemos ganado a través de este complejo recorrido: ya el desarrollo no es algo obvio en los países ricos y siempre deseado en los países pobres; ahora comprendemos que es una tarea que afecta a ambos, porque cuestiona el camino de los primeros y abre nuevos horizontes a los segundos.

\subsection{El pensamiento social cristiano de Benedicto XVI y de Francisco}

Por decirlo en pocas palabras, podemos sintetizar la aportación de Benedicto XVI en torno al concepto de desarrollo humano integral y la de Francisco en torno al de ecología integral. Pero ambas categorías se entienden mejor analizando su origen y fundamento y sus exigencias, así como las circunstancias personales de sus autores.

Benedicto XVI abordó el tema en su única encíclica social: Caritas in veritate. Carta encíclica sobre el desarrollo humano integral en la caridad y en la verdad (2009, en adelante CV). Es una encíclica social, sí, pero de un profundo contenido teológico, como corresponde a la trayectoria personal de Joseph Ratzinger. Es una teología que no anula, sino que ilumina, la reflexión antropológica entrando en diálogo con otras cosmovisiones. Él quiere conmemorar los 40 años de Populorum progressio y lo hace retomando de Pablo VI su concepto de desarrollo integral y su afirmación de que el desarrollo, desde una perspectiva cristiana, debe ser entendido como vocación.

Decir que el desarrollo es, ante todo, vocación implica situarse de lleno en el terreno teológico. Porque implica: $1^{\circ}$ ) que en el origen hay una llamada trascendente, del Dios creador, que invita al hombre a continuar su obra; $2^{\circ}$ ) que el desarrollo es incapaz de darse su sentido último por sí mismo, y que hay que esperarlo de Dios (CV 16-19). La recurrencia del par caridad y verdad es clave: si la Doctrina Social de la Iglesia se ha relacionado siempre con el servicio de la caridad en su sentido más hondo (una caridad que no elude, sino que implica la justicia, CV 6), Benedicto XVI subraya que, cuando la caridad no está arraigada en la verdad,

el gusto de una buena obra frente a la eficiencia productivista, lo razonable frente a lo racional, el trato humano frente al trato racional, etc. (Latouche, 2009, p. 46). 
puede degenerar en sentimentalismo, en emotividad, en buenos sentimientos, o en fideísmo (CV 3). Es cierto que la Iglesia no tiene soluciones técnicas que ofrecer, pero tiene "una misión de verdad que cumplir en todo tiempo y circunstancia en favor de una sociedad a medida del hombre, de su dignidad y de su vocación" (CV 8).

¿A qué verdad se refiere Benedicto XVI? A la verdad sobre el hombre (antropo-logía), la cual deriva, en último término, de la verdad sobre Dios (teo-logía). Este es el armazón de CV, que se despliega luego en torno a dos categorías: don-gratuidad y relacionalidad. A Dios solo se le comprende adecuadamente si se le experimenta como don y gratuidad: y esa experiencia ayuda a descubrir la capacidad del ser humano para el don y la gratuidad. Y el texto se atreve a solicitar que se haga sitio a esta lógica del don en un mundo marcado por las lógicas del mercado y del derecho (CV 34-36.39). Además, Dios se revela como Trinidad, como relacionalidad entre tres personas, de modo que el ser humano no puede concebirse como individuo aislado sino constitucionalmente abierto a los otros, formando una gran familia humana (CV 53-54). Como se ve, esta antropología tiene raíces teológicas, y está llamada a jugar un papel relevante en un mundo tan marcado por el mercantilismo (que excluye el don) y el individualismo (que se resiste al carácter constitutivamente social del ser humano).

CV tiene referencias a muchos problemas concretos que se plantean en el mundo, de forma más aguda tras la crisis de 2007-2008, en relación con el desarrollo de los pueblos: el Estado en el nuevo contexto mundial económico-financiero (CV 24-25), la falta de alimentos y el hambre (CV 27), la empresa y la responsabilidad social (CV 40), la economía civil y de comunión (CV 46-47), la cooperación internacional (CV 47.59.60), la ecología (CV 48-50), las migraciones (CV 62), la necesidad de una autoridad mundial (CV 67), etc. Pero creemos que esta visión antropológico-teológica es la aportación más propia, y novedosa también en la tradición del PSC, para iluminary dar sentido al compromiso por un mundo más justo.

La aportación del papa Francisco tiene rasgos y acentos diferentes. Es el papa que viene del Sur y que ve el mundo con una postura de pastor, sensiblemente preocupado por la misión de la lglesia y por la reforma que se requiere para hacer esta misión más efectiva y creíble. Es lo que expresa en el primer documento relevante de su pontificado como "Iglesia en salida". Ese documento, la Exhortación apostólica Evangelii gaudium (2013, en adelante EG), es considerado como el programa de su pontificado. Esta "Iglesia en salida" (EG 20-23) no puede permanecer ajena a los grandes problemas de nuestro mundo (como adormecida o ensimismada en un cierto confort individualista y espiritualista). EG denuncia con trazos dramáticos la dinámica de una economía de la exclusión (que ya no explota a colectivos enteros, 
sino que excluye a todos aquellos que no sirven ni como productores ni como consumidores, EG 53); además, frente a esta dinámica de exclusión propone el compromiso por la inclusión de los pobres y su desarrollo integral como dimensión esencial de la misión evangelizadora de la Iglesia (EG 176, 186, 202).

Pero el texto que nos interesa sobre todo es el de la que habrá de ser la primera encíclica sobre tema ecológico: Laudato si'. Carta encíclica sobre el cuidado de la casa común (2015, en adelante LS). Aunque ahora el centro es la casa común, no se va a olvidar esa economía de descarte y exclusión. LS, que se abre con un largo capítulo donde se pasa revista a los grandes problemas medioambientales que nos asedian hoy, en seguida va a afirmar que esta crisis ambiental tiene la misma raíz que la crisis social tantas veces denunciada por Francisco. En efecto, la tesis que anima todo el documento es que la crisis social y la crisis medioambiental tienen una única y misma raíz (LS 49 y 139), que él identifica como "antropocentrismo desviado".

¿En qué consiste este antropocentrismo desviado? En el dominio absoluto del paradigma tecnocrático para regular las relaciones del sujeto humano con todo lo que le rodea, personas u otros seres (vivos o no), reduciéndolos a puros medios al servicio de los fines o intereses de cada uno. A esto es a lo que Francisco llama "relativismo": los seres creados no tienen un valor en sí, sino solo por lo que representan para cada sujeto individual y sus intereses (LS 122). No se quiere criticar el desarrollo tecnológico en sí (LS 102), sino esa lógica instrumental propia de este ámbito, que busca la eficiencia de los medios, cuando se pretende aplicar a todos los ámbitos de la existencia (LS 115). Tampoco es un rechazo del antropocentrismo, del llamado "giro antropológico" que caracteriza a todo el pensamiento moderno, sino de su desviación: y esta se da cuando se convierte el sujeto, todo sujeto humano, en señor absoluto de cuanto le rodea.

La propuesta de LS se concreta en una ecología integral, en la medida en que integra todas las relaciones del ser humano con su entorno humano y no humano. Se busca con ello definir mejor el lugar del hombre en el universo, sin caer en un cierto "biocentrismo" (LS 118), pero reconociendo que el hombre no es la última referencia de todo, porque la realidad no humana tiene una consistencia, una razón de ser, que no se agota en estar al servicio del hombre. Si en la tradición cristiana y en la lectura que se ha hecho de los relatos bíblicos de la creación se produjeron desviaciones que pudieron alentar esa apuesta por el dominio absoluto del hombre sobre todo lo creado, Francisco hace una lectura mucho más matizada de aquellas fuentes bíblicas donde aparece como categoría central el cuidado. También aquí $L S$ refuerza desde convicciones creyentes un enfoque de la realidad que tiene su propia consistencia desde posiciones laicas. 


\subsection{El desarrollo como tema ético}

Podemos comenzar diciendo que en esta etapa se encuentran ya consolidados algunos elementos éticos de interés. Por una parte, el concepto mismo de desarrollo ha pasado de ser un tema puntual o sectorial (afecta a un colectivo delimitado de personas y pueblos) a ser una tema transversal (afecta a todo ser humano e invita a cuestionar estilos de vida demasiado incuestionados). Por otra parte, hemos avanzado en cuanto a la responsabilidad en juego: ya no atañe solo a los pueblos atrasados, ni siquiera también a los desarrollados, sino a la comunidad mundial como nuevo sujeto ético (como veremos en seguida).

El concepto de desarrollo ha adquirido una consistencia significativa en torno a la categoría de las capacidades de Amartya Sen, que se ha erigido en referente indiscutible, aunque no falten algunos críticos de su pensamiento. Sen significa centrar el desarrollo en la persona, que es la que tiene que asumir su propio desarrollo en función de sus aspiraciones.

Además, junto al concepto de desarrollo hay otros conceptos éticos que adquieren una relevancia nueva. Al menos cuatro:

- Solidaridad: en un mundo interdependiente nadie puede actuar como si su acción no tuviera repercusiones sobre otros. Todos somos responsables de todos. Pero este principio más general debe buscar cauces operativos para hacerse efectivo. Y la comunidad mundial ofrece pistas para ello.

- Subsidiariedad: se suele interpretar como justificación de la iniciativa y la autonomía de los entes menores frente a los superiores (los Estados miembros frente a las instituciones europeas, las comunidades autónomas frente al Estado español). Pero la subsidiariedad implica también que los entes superiores intervengan allí donde los inferiores no tienen capacidad de alcanzar objetivos legítimos. De nuevo aquí, la comunidad mundial adquiere una significatividad nueva.

- Sostenibilidad: tener en cuenta las generaciones futuras ya no es una cuestión de calculo previsional, sino de responsabilidad. De nuevo aquí se plantea quién asume esta responsabilidad.

- Cuidado: supone una actitud y un talente diferente ante la realidad exterior. Frente a la actitud de conquista y de dominio sobre algo externo lo que "se nos resiste", ahora comprendemos la necesidad de una actitud de cuidado ante lo que "se nos da" y que constituye nuestra morada (nuestra casa común). Lo ilimitado deja de serlo, para convertirse en limitado, escaso, digno de cuidado. 
Todos estos conceptos remiten, como ya hemos ido indicando, al de comunidad mundial. Quizás puede argumentarse que no es este un concepto ético, pero es difícil negar que es un sujeto ético que adquiere una relevancia especial en el mundo globalizado.

Por comunidad mundial entendemos, en una primera aproximación, el conjunto de habitantes del planeta Tierra. Desde siempre hemos compartido el planeta, pero viviendo diseminados y aislados (por el número, en relación con el territorio, y por los medios para comunicarnos). Hoy esto ha cambiado: por densidad demográfica y por los avances en las técnicas de comunicación.

En aquel mundo antiguo esa sociedad de sociedades se organizó en unidades políticas, que, en la época moderna tomaron la configuración de Estados, a los que se consideraban con capacidad para relacionarse entre sí como iguales. Hoy esa estructura resulta ya insuficiente, una insuficiencia que se agiganta en el contexto de la globalización económica. En aquel escenario anterior, la liberalización económica dentro de las sociedades del siglo XIX y comienzos del XX, auspiciada por la ideología liberal, llevó a crisis que obligaron a los poderes públicos a asumir una iniciativa que se les había venido negando hasta entonces. Hoy, la liberalización económica a escala mundial produce efectos equivalentes, que demandarían la intervención de una instancia reguladora de ese mercado globalizado. Pero esta instancia no existe, está por crear. Es uno de los grandes retos del presente.

La creación de una instancia de gobierno mundial tiene evidentes dificultades, pero también se comienzan a vislumbrar algunos pasos prometedores.

Las dificultades son de dos órdenes:

- Cualquier instancia superior con competencias universales entraría en conflicto con el principio fundamental de soberanía del Estado, y de no subordinación a ninguna autoridad por encima de él. ¿¿Cómo articular entonces estas dos instancias? En este sentido, habría que excluir la idea de un Estado más grande, dotado ahora de dimensión planetaria.

- Una concentración de poder de esa envergadura y carente de algún mecanismo de control asusta a cualquiera. No sería deseable por el riesgo que comportaría de que se abusara de él.

Entre las propuestas que se han sugerido merecen cierta atención las sugerencias contenidas en un informe que los obispos de la Unión Europea encargaron a un 
grupo de expertos (COMECE, 2001). Cabría pensar en un sistema formado por tres pilares:

- Los organismos internacionales existentes comenzando por la ONU, que precisarían una mejor definición de su composición y competencias.

- La colaboración entre los Estados a través de alianzas estables, y con una orientación más marcada por el bien común universal que por los intereses de los que se alían.

- La sociedad civil y los agentes sociales, con tal que se articulen en redes que puedan tener una incidencia efectiva a escala mundial (y las tecnologías modernas ofrecen muchas posibilidades en este terreno).

Hay que concluir estas reflexiones mencionando las dos iniciativas de Naciones Unidas en estas últimas décadas: los Objetivos de Desarrollo del Milenio (ODM) y los Objetivos de Desarrollo Sostenible (ODS). Interesan aquí, no para entrar en un análisis detallado de sus contenidos, sino para destacar el avance que suponen como acción de esta comunidad mundial incipientemente organizada.

Este avance, aunque tímido e insuficiente, puede verse, ante todo, en el hecho mismo de asumir unos objetivos comunes, frente a la práctica tradicional de señalar unas reglas de juego para que los distintos actores internacionales persigan cada uno sus intereses. Además, se reconoce una responsabilidad compartida, que se propone plasmar en una alianza efectiva (partnership). De fondo late, sin duda, esa comunidad mundial (la humanidad) cuyas necesidades no pueden quedar satisfactoriamente atendidas por las comunidades nacionales y sus respectivos Estados.

Ya en la Declaración del Milenio, del año 2000, se habla de una "responsabilidad colectiva (...) respecto de todos los habitantes del planeta", de aunar esfuerzos amplios y sostenidos para crear un futuro común" (...) [para] lograr que la mundialización sea plenamente incluyente y equitativa". Esta responsabilidad común "debe ser compartida por las naciones del mundo y ejercerse multilateralmente", $y$ las Naciones Unidas "deben desempeñar un papel central a ese respecto" (ONU, 2000, nn. 2, 5, 6).

De los ODM ha sido especialmente destacado en este sentido el $n^{\circ} 8$ ("Fomentar una alianza mundial para el desarrollo"). A diferencia de los otros ODM, en este todas las acciones propuestas corresponden a los países ricos, para eliminar los grandes obstáculos al desarrollo que ellos crean: se refieren a las reglas que regulan 
el comercio internacional, a la deuda externa que atenaza a los países pobres, a la ayuda al desarrollo y a la transferencia de tecnología. Este reconocimiento de obligaciones de los países ricos ha sido considerado por algunos como el paso más importante dado desde el Pacto de Naciones Unidas sobre los Derechos Económicos, Sociales y Culturales (Fukuda-Parr, 2006): allí se hablaba de obligaciones de cada Estado dentro de su territorio, aquí son obligaciones internacionales del Estado más allá de sus fronteras.

Un horizonte algo más ambicioso se proponen los ODS y la Agenda 2030. Concretamente el ODS 17 ("Fortalecer los medios de implementación y revitalizar la Alianza Mundial para el Desarrollo Sostenible") se sitúa en continuidad con el ODM 8, pero las alianzas que ahora se piden se dirigen, no solo a los Estados, sino también a la sociedad toda: alianzas entre la esfera pública y la privada y con las organizaciones de la sociedad civil.

Pero ha sido el ODS 16 ("Promover sociedades pacíficas e inclusivas para el desarrollo sostenible, facilitar el acceso a la justicia para todos y construir a todos los niveles instituciones eficaces e inclusivas que rindan cuentas") el tenido por uno de los avances más importantes de la Agenda 2030 respecto a los ODM (Sanahuja, 2018). En él se pide crear lo que son las condiciones de posibilidad para un desarrollo auténtico y pleno: la paz y la seguridad, los derechos humanos y las libertades democráticas (Camacho, 2020, pp. 318-323).

\section{Conclusiones}

Hemos querido poner de manifiesto cómo la reflexión ética se ha ido abriendo paso en los estudios y políticas sobre el desarrollo y cuál ha sido el papel del PSC en este proceso. Como síntesis final de recorrido efectuado parece justo reconocer que el PSC fue pionero en la reflexión ética sobre el desarrollo, y ha seguido acompañando luego estudios realizados desde otras perspectivas cosmovisionales.

Esta aportación no se ha centrado tanto la propuesta de políticas concretas cuanto en inspirar esas políticas con una visión del ser humano que está basada en la tradición cristiana, pero que puede ser entendida y asumida desde otras cosmovisiones. La centralidad de la persona hace de esta el fin de todo desarrollo, desplazando a la categoría de medio lo que fue en un primer momento el objetivo último (económico). Y la persona no es solo fin del desarrollo en cuanto destinatario de este: es también sujeto de su propio desarrollo. De lo que se trata es, no de 
dar, sino de capacitar a cada sujeto para que haga realidad sus aspiraciones en todos los niveles de la existencia humana (desarrollo integral).

Este enfoque personal se complementa con otras dos coordenadas, que fueron objeto de atención por separado, pero que terminaron uniéndose en una visión unificada: desarrollo solidario y desarrollo sostenible, desarrollo de todos y desarrollo cuidadoso con el entorno natural. La igualdad de todos los seres humanos, que consagra el reconocimiento del derecho al desarrollo como síntesis de todos los derechos humanos, y el cuidado de la casa común: he ahí los dos grandes retos de las políticas actuales de desarrollo. De este modo el concepto de desarrollo no afecta ya solo a los pueblos más atrasados, atañe a la humanidad entera y obliga a cuestionar estilos arraigados en algunos pueblos que son incompatibles con la igualdad de todos y el cuidado de la casa común.

Ahora bien, no basta definir las exigencias de un auténtico desarrollo. Es preciso además preguntarse en quién recae la responsabilidad de ese desarrollo. Y aquí los avances pueden graduarse así:

- El carácter personal del desarrollo explica que su primer responsable sea el propio sujeto humano, cada persona. Pero ello requiere que disponga de las condiciones para hacer realidad ese desarrollo.

- Estas condiciones deben ser garantizadas por la sociedad a través de sus estructuras políticas (derechos sociales y ecos, derecho al desarrollo).

- Pero la responsabilidad de los Estados no se circunscribe a su propio territorio. La interdependencia de nuestro mundo exige que todos cuiden del sistema de relaciones entre los pueblos (económicas, políticas, sociales...).

- Y, en un mundo tan globalizado, cada vez resulta más urgente dotarse de una instancia de gobierno mundial que se ocupe del bien común de todos y del cuidado de la casa común, por encima de fronteras estatales, como vía para que este desarrollo no se quede en grandes principios y en difusos ideales.

\section{Bibliografía}

BarAN, P. (1957). La economía política del crecimiento, Fondo de Cultura Económica.

CAMACHO, I. (1998). Doctrina Social de la Iglesia. Una aproximación histórica, San Pablo ( $3^{\mathrm{a}}$ edición). 
- (2005). "El pensamiento social de Juan Pablo II. Líneas básicas de sus tres encíclicas sociales", Revista Fomento Social, 60, 189-218.

- (2020). "Subsidiariedad y comunidad mundial" (ODS 16, 17), en J. M. LARRÚ (ed.), Desarrollo humano integral y Agenda 2030. Aportaciones del pensamiento social cristiano a los Objetivos de Desarrollo Sostenible (pp. 297-328), Editorial Católica.

- (2021). "Antropología cristiana, modelos de sociedad e ideologías contemporáneas", en América Latina ante el cambio civilizatorio actual, ODUCAL (en prensa).

Cançado Trindade, A. A. (1990). "Legal Dimensions of the Right to Development as a Human Right: some Conceptual Aspects", Revista del Instituto Internacional de Derechos Humanos, 12, 88-92.

- (1998). "The interdependence of all human rights. Obstacles and challenges to human rights implementation", International Social Science Journal, 50, 51 4-523.

Colmenarejo, R. (2016). "Enfoque de Capacidades y Sostenibilidad: Aportaciones de Amartya Sen y Martha Nussbaum", Ideas y Valores 160, 121-149.

COMECE (2001). El sistema de gobierno global. Nuestra responsabilidad en hacer de la globalización una oportunidad para todos. Informe para los Obispos de la COMECE, COMECE, Bruselas.

Comisión Mundial del Medio Ambiente y Desarrollo (1988). Nuestro futuro común, Alianza Editorial.

CONSEJO DE REDACCIÓN (2005). "Desarrollo económico y social: teorías, propuestas", Revista de Fomento Social, 60, 11-38.

CORTINA ORS, A. (2019). "Superando los límites de la ciencia ensimismada: el compromiso ético de la universidad con el desarrollo humano", Revista de Fomento Social, 74, 105-119.

Équipe d'Économie et Humanisme (1966). "Louis-Joseph Lebret - 1897-1966", Économie et Humanisme, 170, 2-6.

FUKUDA-PARR, S. (2006). "Millennium DevelopmentGoal 8: Indicators for International Human Rights Obligations?", Human Rights Quartely, 28, 966-997. 
GASPER, D. (2008). "Denis Goulet and the Project of Development Ethics: Choices in Methodology", Focus and Organization, Journal of Human Development and Capacities.

GómEz ISA, F. (2012). "El derecho al desarrollo en el 25 aniversario de la Declaración sobre el derecho al desarrollo", Derechos y Libertades, 26, 181-204.

Goulet, D. (1960). "Pour une éthique moderne du développement", Développement et Civilisations, 3 (September), 10-23.

- (1974). "L. J. Lebret. Pioneer of development ethics", en Development ethics at Work. Explorations - 1960-2002, 50-62, Routledge (2006).

- (1989). "Tareas y métodos en la ética del desarrollo", Revista de Filosofía de la Universidad de Costa Rica, 27, 293-305.

- (1999). "Ética del Desarrollo, Guía teórica y práctica", IEPALA [Development Ethics: A Guide to Theory and Practice, 1995].

HidAlgo-CAPITÁn, A. L. (1998). El pensamiento económico sobre desarrollo. De los mercantilistas al PNUD, Universidad de Huelva.

- (2011). "Economía Política del Desarrollo. La construcción retrospectiva de una especialidad académica", Revista de Economía Mundial, 28, 279-320.

HouÉE, P. (1997). Un éveilleur d'humanité, Louis-Joseph Lebret, Les Éditions de I'Atelier.

KeleHER, L. (2019). "Integral human development. Development of every person and of the whole person", en Routledge Handbook of Development Ethics 29-34. Routledge.

Koolumans, P. H. (1990). "Human Rights - Universal Panacea? Some Reflections on the so-called human rights of the third generation", Netherland International Law Review, 37, 315-329.

LAtouche, S. (2009). Pequeño tratado del decrecimiento sereno, Icaria.

LEBRET, L.-J. (1961). Dynamique concrète du développement, Économie et Humanisme, Les Éditions Ouvrières [Dinámica concreta del desarrollo, Herder 1966] 
MÀrIA, J. F. (2000). "El Consenso de Washington iparadigma económico del capitalismo triunfante?", Revista Fomento Social, 55, 29-45

M'BAYE, K (1972). "Le droit au développement comme un droit de l'homme", Revue de Droits de l'Homme, 2-3, 503-534.

ONU (2000). Declaración del Milenio (A/RES/55/2*).

- (2001). Guía general para la aplicación de la Declaración del Milenio. Informe del Secretario General (A/56/326) 6 septiembre 2001.

PNUD (1990). Desarrollo Humano, Informe 1990. Concepto y medición del desarrollo humano, Tercer Mundo Editores.

- (1991). Desarrollo Humano, Informe 1991. Financiación del desarrollo humano, Tercer Mundo Editores.

- (1997). Informe sobre desarrollo humano 1997. Desarrollo humano para erradicar la pobreza.

PreBISCH, R. (1949). "El desarrollo de América Latina y algunos de sus principales problemas", El Trimestre Económico, 16(3), 347-431. Consulta en el repositorio de la CEPAL: El desarrollo económico de la América Latina y algunos de sus principales problemas | Repositorio Digital | Comisión Económica para América Latina y el Caribe (cepal.org).

- (1963). Hacia una dinámica del desarrollo latinoamericano, Fondo de Cultura Económica.

Rostow, W. W. (1960). The Stages of Economic Growth: A Non-Communist Manifesto, Cambridge University Press.

Sanahuja, J. A. (2018). "Paz, seguridad y gobernanza: el ODS 16 y la Agenda 2030 de desarrollo sostenible", en Objetivos de desarrollo sostenible y derechos humanos: paz, justicia e instituciones sólidas / derechos humanos y empresas, Instituto de Estudios Internacionales y Europeos Francisco de Vitoria de la Universidad Carlos III, 27-54.

SEN, A. (2000). Desarrollo y libertad, Planeta [original: Development as Freedom, 1999]. 
Stiglitz, J. E. (2002). El malestar de la globalización, Taurus.

Wimlamson, J. (2002). "What Washington Means by Policy Reform", en Latin American Adjustment: How Much Has Happened? Peterson Institute for International Economics.

WORLD BANK (1990). World Development Report 1990. Poverty, Oxford University Press.

\section{( SALTERRAE}

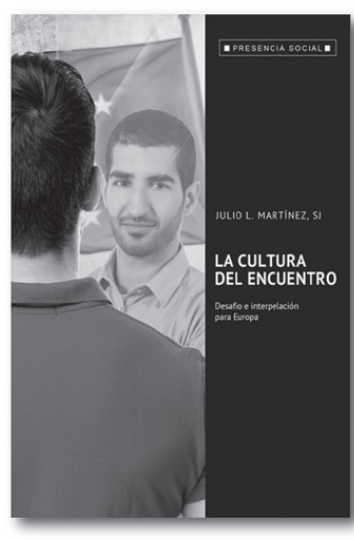

Julio L. MARTíneZ, S.

J. (ed.)

La cultura del encuentro

Desafío e interpelación a Europa

$272 \mathrm{pp}$.

P.V.P.: 14,90

El rector de la Universidad Pontificia Comillas llama a «la cultura del encuentro» comprendida como aquella que está capacitada para derribar todos los muros que aún dividen el mundo... «Donde hay muro, hay cerrazón de corazón». Inspirado en las palabras del papa ante el Congreso de los Estados Unidos - - es mi deber construir puentes y ayudar en lo posible a que todos los hombres y mujeres puedan hacerlo»-. Partiendo de los cuatro principios que orientan en el Evangelii gaudium hacia la convivencia social y la construcción de un pueblo donde las diferencias se acercan en un proyecto común: «el tiempo es superior al espacio», «la unidad prevalece sobre el conflicto», «la realidad es más importante que la idea» $\mathrm{y}$ «el todo es superior a la parte».

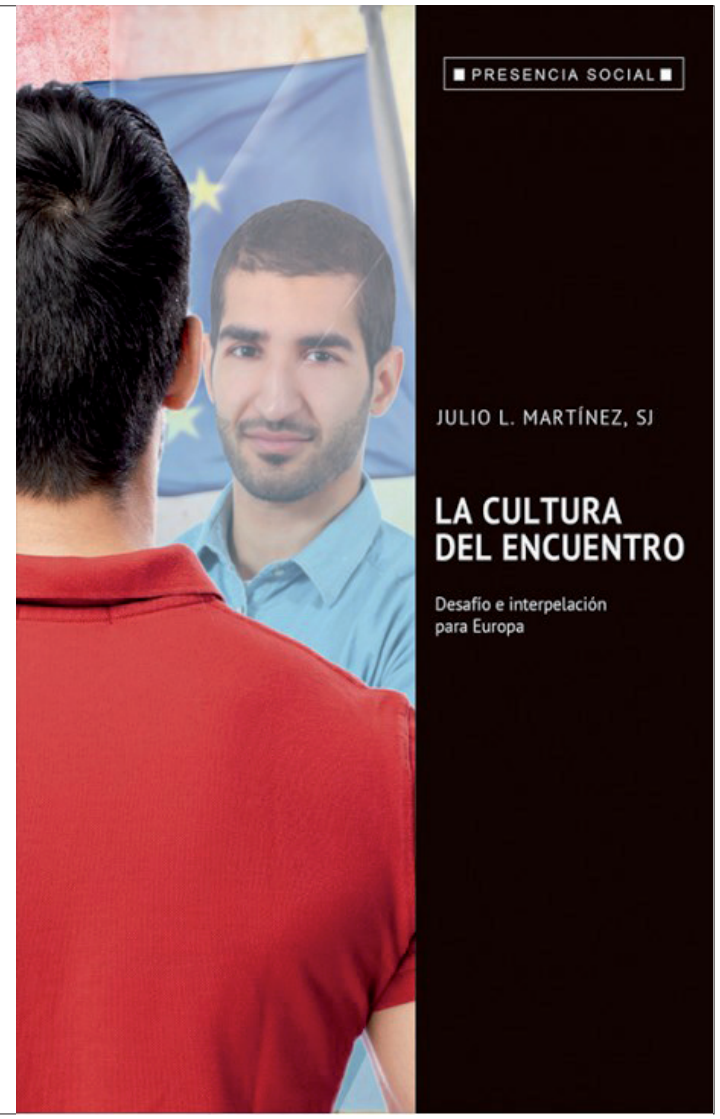

